\title{
COMPOSIÇÃO ELEMENTAR DO MATERIAL PARTICULADO PRESENTE NO AEROSSOL ATMOSFÉRICO DO MUNICÍPIO DE SETE LAGOAS, MINAS GERAIS
}

Paula Guimarães Moura Queiroz, Vanusa Maria Feliciano Jacomino* e Maria Ângela de Barros Correia Menezes

Centro de Desenvolvimento da Tecnologia Nuclear/Comissão Nacional de Energia Nuclear, CP 941, 30123-970, Belo Horizonte - MG, Brasil

Recebido em 9/8/06; aceito em 8/1/07; publicado na web em 24/7/07

ELEMENTAL COMPOSITION OF THE PARTICULATE MATTER PRESENT IN THE ATMOSPHERIC AEROSOLS OF SETE LAGOAS, MG. The main objective of this study was the identification of sources generating particulate matter in the atmospheric aerosols of Sete Lagoas, Minas Gerais. The measurement of the mineral composition was accomplished by X-ray diffractometry and the elemental concentration by neutron activation analysis. The results showed that $\mathrm{Al}, \mathrm{Cl}, \mathrm{Cu}, \mathrm{Fe}, \mathrm{K}, \mathrm{Mg}$ and $\mathrm{Na}$ are the predominant chemical elements in the total suspended particles (TPS). The presence of $\mathrm{Na}, \mathrm{Ba}, \mathrm{Cl}, \mathrm{Cu}, \mathrm{Eu}, \mathrm{Fe}$ and $\mathrm{Sm}$ in those particles with aerodynamic diameter smaller than $10 \mu \mathrm{m}\left(\mathrm{PM}_{10}\right)$, indicates that soil dust and ceramic and pig iron industries are the main sources of air quality degradation in the region.

Keywords: particulate matter; air pollution; trace element.

\section{INTRODUÇÃO}

O desenvolvimento industrial e urbano tem originado em todo o mundo um aumento crescente da emissão de poluentes atmosféricos. O acréscimo das concentrações dessas substâncias, a sua deposição no solo, nos vegetais e nos materiais são fatores responsáveis por danos à saúde humana, redução da produção agrícola, danos às florestas, degradação de construções e de obras de arte e, de forma geral, causam desequilíbrios nos ecossistemas.

Os poluentes lançados diretamente na atmosfera pela fonte que os produziu são chamados de poluentes primários; aqueles formados na atmosfera por reações químicas que ocorrem entre os poluentes primários e os constituintes naturais do ar são chamados de poluentes secundários. De acordo com a legislação ambiental vigente $^{1}$ no País, o material particulado presente na atmosfera é considerado um poluente primário.

Material particulado é o termo utilizado para uma mistura de partículas sólidas e gotas de líquidos encontrados na atmosfera ${ }^{2}$. Algumas dessas partículas podem ser grandes, escuras e, portanto, visíveis, tais como a fumaça ou a fuligem. Outras são tão pequenas que somente podem ser vistas através de um microscópio. A sua fonte de origem pode ser natural ou artificial. Dentre as fontes naturais podem ser citadas aquelas evaporadas do mar sob a forma de spray, pólens, poeiras e vulcões ou outras erupções geotérmicas. Como fontes artificiais têm-se, por exemplo, motores de veículos, caldeiras industriais e fumaça do cigarro. Dependendo dos tipos de fontes existentes e de suas interações com outros componentes presentes na atmosfera, as composições químicas dos poluentes, bem como os impactos causados à saúde humana podem ser diferentes ${ }^{3}$. As queimadas também são fontes importantes de poluição do ar, podendo causar problemas respiratórios sérios à população ${ }^{2}$.

O material particulado pode ser dividido, basicamente, em duas modas definidas por intervalos de tamanho onde se tem maior concentração de partículas: a moda das partículas finas, menores que 2,5 $\mu \mathrm{m}$ de diâmetro aerodinâmico e a moda de partículas grossas,

*e-mail: vmfj@cdtn.br maiores que 2,5 $\mu \mathrm{m}$. Essa divisão é bastante conveniente, uma vez que frações de diâmetros aerodinâmicos diferentes possuem propriedades físicas e químicas distintas ${ }^{3}$.

A moda grossa é geralmente constituída por partículas primárias, formadas a partir de processos mecânicos, como ressuspensão de poeira de solo por ventos, sal marinho, cinzas de combustão e emissões biogênicas naturais ${ }^{4}$. A moda fina contém partículas primárias geradas por processos de combustão por indústrias, veículos e partículas secundárias, provenientes da formação de partículas na atmosfera a partir de gases, como por exemplo, a formação de sulfatos a partir de $\mathrm{SO}_{2}$. Estas, por sua vez, possuem um tempo de permanência de dias a semanas na atmosfera e podem ser transportadas a longas distâncias por correntes de ar favoráveis, interferindo na química e na física da atmosfera, não somente em escala local, mas também em escalas regional e global ${ }^{3}$.

O particulado inalável (conjunto que engloba as partículas das modas fina e grossa menores que $10 \mu \mathrm{m}$ ) é constituído por sulfatos, nitratos, amônia, aerossol carbonáceo, sais marinhos $(\mathrm{NaCl})$, elementos de solo (Al, $\mathrm{Ca}, \mathrm{Fe}, \mathrm{Si}$, Ti), metais ( $\mathrm{Cd}, \mathrm{Cr}, \mathrm{Cu}, \mathrm{Ni}, \mathrm{Pb}$, $\mathrm{V}, \mathrm{Zn}$ e outros) e água 5 .

Diversos estudos ${ }^{6-9}$ relacionados aos efeitos da poluição na saúde mostram que a exposição ao particulado mais fino pode causar mortes prematuras e problemas respiratórios, pois é esta a fração que atinge as vias respiratórias inferiores (nível alveolar), onde os mecanismos de expulsão destes poluentes não são eficientes. Contudo, o particulado grosso é preocupante uma vez que tende a se acumular nas vias respiratórias superiores, agravando problemas tais como o da asma.

Os padrões de qualidade do $\operatorname{ar}^{1}$ definem legalmente o limite máximo para a concentração de um determinado poluente na atmosfera, que garanta a proteção da saúde e o bem-estar das pessoas. Os governos estaduais e suas agências ambientais vêm regulamentando as emissões de uma variedade de fontes de degradação ${ }^{10}$. As legislações nacional e estadual estabelecem critérios de qualidade do ar considerando apenas a concentração e a granulometria do material particulado sem, no entanto, considerar a sua composição química. Ao contrário, muitos países estão identificando os aerossóis presentes em suas atmosferas e relacionando a concen- 
tração de seus constituintes com os casos de saúde registrados e com as fontes de emissão local. Várias pesquisas ${ }^{11-14}$ relacionam o tamanho, a área de superfície, assim como a composição química como fatores importantes na determinação dos efeitos à saúde quando associados ao material particulado.

Uma vez que na atmosfera as concentrações de elementos traços se encontram em níveis muito baixos (da ordem de traços, ou seja, ppm ou ppb por $\mathrm{m}^{3}$ de ar) existe a necessidade do uso de técnicas analíticas apropriadas que permitam a medida de forma adequada. Embora exista uma série de técnicas disponíveis, o uso de técnicas nucleares, tais como a espectrometria de fluorescência de raios-X (FRX), o PIXE ("Particle Induced X-ray Emission") e a análise por ativação neutrônica (AAN), apresenta uma série de vantagens em relação aos outros métodos químicos convencionais normalmente utilizados, entre elas ${ }^{15}$ : a eliminação da necessidade de ataque químico às amostras, independência em relação à forma química dos elementos, necessidade de pequena quantidade de amostra, além da precisão, exatidão e sensibilidade, permitindo a determinação dos elementos em concentrações da ordem de parte por bilhão (ppb) até porcentagens do elemento na amostra.

O município de Sete Lagoas, localizado na região de planejamento Centro-Oeste do estado de Minas Gerais, concentra um grande número de pequenas e médias indústrias, em especial, as usinas de produção de ferro-gusa a carvão vegetal, bem como indústrias de fabricação de cerâmica, mineradoras de calcário, entre outras. Relatórios técnicos, gerados a partir dos resultados de monitoramento da qualidade do $\operatorname{ar}^{16}$ neste município, demonstraram que em alguns dos pontos de amostragem, os níveis de material particulado na atmosfera local são elevados e que, dependendo da época do ano, podem estar acima dos limites estabelecidos pela legislação ambiental. Este fato, associado às informações relativas à meteorologia local, às taxas de emissão de material particulado e às características peculiares das tipologias industriais predominantes na região, levou a agência ambiental estadual do estado de Minas Gerais a deliberar normativas para disciplinar o lançamento de efluentes atmosféricos na região.

Diante da necessidade de regulamentar as emissões atmosféricas como forma de garantir uma melhoria da qualidade do ar no município de Sete Lagoas, o principal objetivo deste trabalho foi a realização de um estudo experimental para caracterização química do material particulado presente no aerossol atmosférico utilizando técnicas nucleares, ou mais especificamente, a técnica de análise por ativação neutrônica. Os resultados obtidos serviram como base para identificação da origem do material particulado presente na atmosfera por meio do uso de modelos receptores ${ }^{15,17}$.

\section{PARTE EXPERIMENTAL}

\section{Seleção do ponto de amostragem}

A primeira etapa do trabalho constitiu na escolha do ponto de amostragem de material particulado. Para tanto, foi feita uma avaliação inicial da região em estudo de forma que o ponto selecionado sofresse a influência do maior número possível de fontes emissoras contribuintes de material particulado, fossem elas de origem natural ou artificial (poeiras, fumaças e aerossóis emitidos para a atmosfera por indústrias, veículos, construção civil etc). Outro critério utilizado foram as condições de uso e ocupação do solo no entorno da estação de amostragem de qualidade do ar. A partir daí, foi selecionado um ponto cujas circunvizinhanças possuem características urbanas, acomodando instalações industriais, comerciais, residenciais (uni e multifamiliares) e de usos públicos. À exceção da margem da ferrovia existente nas proximidades do local, o solo encontra-se impermeabilizado, as vias de acesso nas proximi- dades são asfaltadas e possuem tráfego intenso, inclusive de carga pesada. Vizinhas à estação encontram-se em funcionamento atividades ligadas à produção de ferro-gusa a carvão vegetal, fabricação de cerâmica, de leites e derivados, tecelagens, marmorarias, serralherias e fábrica de produtos de fibra de vidro ${ }^{17}$.

\section{Amostragem do material particulado}

A amostragem do material particulado foi realizada no período de 11/1/2005 a 14/2/2005. A etapa de planejamento dos experimentos incluiu também a realização de vários testes para determinar qual seria a matriz de filtro mais adequada para coleta e análise da composição química do material particulado presente nos aerossóis atmosféricos. Foram analisadas matrizes de filtro de celulose e microssílica (ou microquartzo). A avaliação da composição de cada filtro permitiu verificar a interferência dos seus elementos constituintes na análise da concentração dos elementos traços quando da aplicação da técnica de ativação neutrônica.

O filtro que apresentou melhor eficiência na retenção de material particulado foi o de microssílica e o filtro com menor número de constituintes e interferências foi o de celulose. Entretanto, em decorrência do custo elevado do filtro de microssílica, optou-se pela utilização de filtros de celulose para a amostragem das Partículas Totais em Suspensão (PTS) e de filtros de microssílica para as Partículas Inaláveis $\left(\mathrm{PM}_{10}\right)$.

A concentração média das partículas totais em suspensão foi determinada por meio da análise de amostras coletadas isocineticamente em um amostrador de grande volume (AGV), também conhecido por Hi-Vol ("High-Volume"), fabricado pela Energética ${ }^{18}$. A vazão média de operação do equipamento foi de $1,4 \mathrm{~m}^{3} \mathrm{~min}^{-1}$ obedecendo, portanto, as recomendações do fabricante de vazões médias entre 1,1 e $1,7 \mathrm{~m}^{3} \mathrm{~min}^{-1}$.

A concentração média de partículas inaláveis foi obtida por meio da análise de amostras coletadas em um amostrador de grande volume com cabeça de separação por impactação inercial, conhecido como $\mathrm{PM}_{10}$, fabricado pela Energética ${ }^{18}$. Como a velocidade do ar é um parâmetro crítico para a manutenção do ponto de corte de $10 \mu \mathrm{m}$, a vazão média de operação foi mantida em 1,13 m min $^{-1}$, com desvios máximos de $10 \%$, em condições reais de temperatura e pressão.

A coleta de PTS foi realizada em ciclos de $12 \mathrm{~h}$, correspondentes aos horários diurno e vespertino/noturno. Por sua vez, a coleta de $\mathrm{PM}_{10}$ foi realizada em ciclos de $24 \mathrm{~h}$. A escolha de cada regime de operação se deu com base nas recomendações da $\mathrm{ABNT}^{19,20}$, que sugere que a vazão média de operação dos equipamentos seja mantida a mais constante possível durante o procedimento de amostragem. No total foram coletadas 87 matrizes de filtros, sendo 30 filtros de microssílica e 57 filtros de celulose.

A determinação da distribuição do tamanho das partículas presentes nos aerossóis atmosféricos foi feita com um dispositivo acoplado ao amostrador de grande volume denominado impactador em cascata (IC), do tipo Sierra Model 235, fabricado por Sierra Instruments, Inc. O IC utilizado é um dispositivo que retira o material particulado do ambiente sob condições isocinéticas e segrega o aerossol em vários estágios em cascata. O IC possui 6 estágios de separação com pontos de corte em $10 ; 10$ a 4,2; 4,2 a 2,1; 2,1 a 1,$3 ; 1,3$ a 0,7 e menores que $0,7 \mu \mathrm{m}$.

\section{Metodologia analítica}

A gravimetria foi a metodologia utilizada para determinar a concentração média do material particulado coletado nos filtros usados para amostragem. Para tanto, a massa do filtro foi medida 
antes e após a amostragem; assumindo-se que a diferença entre elas corresponderia ao material depositado durante o período de coleta. Conhecendo-se a massa e sabendo-se o volume de ar amostrado, registrado no totalizador do equipamento amostrador, pode-se determinar a concentração média do material particulado coletado.

Para a pesagem dos filtros foi utilizada uma balança digital de precisão de 0,1 mg, da marca Automarte, série AS5500. Antes de cada pesagem, os filtros permaneceram $24 \mathrm{~h}$ em um dessecador, composto de prateleiras treliçadas, possuindo na sua base uma bandeja coberta de sílica-gel.

A composição mineralógica do material particulado total em suspensão (PTS) e das partículas inaláveis $\left(\mathrm{PM}_{10}\right)$ foi determinada pela técnica de difração de raios-X, método pó ${ }^{17}$. As análises levaram em consideração as intensidades das principais reflexões das fases e as comparações entre as mesmas, avaliando-se as quantidades relativas dos teores dos minerais em cada amostra analisada.

A análise para determinação da composição elementar das amostras de filtros de celulose e microssílica foi realizada por meio da técnica de ativação neutrônica, método- $\mathrm{k}_{0}^{21}$. Para a aplicação da técnica, as amostras foram irradiadas no reator Triga Mark I IPR-R1, localizado no CDTN/CNEN, Belo Horizonte. Inicialmente, todas as amostras foram pesadas e acondicionadas em tubos de polietileno. A irradiação foi feita na mesa giratória sob fluxo médio de nêutrons térmicos de $6,6 \times 10^{11}$ nêutrons $\mathrm{cm}^{2} \mathrm{~s}^{-1}$, estando o reator a uma potência de $100 \mathrm{~kW}$. Cada batelada de amostras irradiadas, fossem elas de filtro de celulose ou de microssílica, foi analisada acompanhada por um branco de filtro correspondente e de comparadores de sódio em triplicata, necessários para o cálculo de concentração. Além disso, todas as análises foram acompanhadas de amostras de materiais de referência ${ }^{17,22}$, com o objetivo de se verificar a exatidão da técnica e garantir a reprodutibilidade das análises.

As amostras foram irradiadas seguindo os esquemas: $4 \mathrm{~min}$, para a determinação de elementos cujos radionuclídeos são de meias-vidas curtas $(<3 \mathrm{~h}) ; 8 \mathrm{~h}$, para os de meias-vidas médias (de 4 a 12 dias) e longas (>30 dias). Após um tempo de espera adequado para o decaimento dos radionuclídeos interferentes, foi executada a espectrometria gama em um sistema de detecção composto de um detector HPGe, Canberra (modelo GC1518, resolução de 1,85 $\mathrm{keV}$ para a energia de $1332 \mathrm{keV}$ do ${ }^{60} \mathrm{Co}$ ), conectado à eletrônica específica e programa de aquisição de espectros Maestro, Ortec.

Diversos elementos foram determinados - $\mathrm{Al}, \mathrm{As}, \mathrm{Ba}, \mathrm{Cl}, \mathrm{Cu}$, $\mathrm{Eu}, \mathrm{Fe}, \mathrm{K}, \mathrm{Mg}$, Na Mn, Sm, Ti e V - nas amostras de filtro; entretanto, outros elementos de interesse sob ponto de vista ambiental, tais como chumbo $(\mathrm{Pb})$, níquel $(\mathrm{Ni})$, silício $(\mathrm{Si})$, cádmio $(\mathrm{Cd})$ e cálcio $(\mathrm{Ca})$, não puderam ser determinados. $\mathrm{O} \mathrm{Pb}$, porque a reação $(\mathrm{n}, \gamma)$ durante a irradiação produz um radionuclídeo que não é emissor gama, o que inviabiliza a espectrometria gama; o Si não têm secção de choque adequada para ser ativado por nêutrons térmicos; $\mathrm{Ca}, \mathrm{Cd}$ e Ni apresentam baixa seção de choque a nêutrons térmicos, significando que, nas condições técnicas de análise, só em concentrações maiores que $1 \%$ é que poderiam ser dosados.

\section{Modelo receptor}

Como mencionado anteriormente, a utilização de modelos receptores teve por finalidade identificar as principais fontes de emissão do material particulado coletado durante a realização dos experimentos de amostragem da qualidade do ar no município de Sete Lagoas, MG. O modelo receptor usado no presente estudo foi aquele baseado no método das Componentes Principais, o qual faz parte da Análise Fatorial (AF) ${ }^{23,24}$.

A AF está relacionada com a explicação da estrutura de variância- covariância por meio de poucas combinações lineares das variáveis originais. Esta metodologia aplicada dentro do enfoque da poluição do ar é considerada como um modelo receptor porque trata o problema a partir dos dados obtidos junto ao receptor ${ }^{3}$. Ela consiste, basicamente, de técnicas estatísticas desenvolvidas para examinar a estrutura intrínseca que existe em um grande conjunto de dados, isto é, para extrair as informações essenciais dos dados, as quais não são percebidas em uma análise individual de cada caso.

Uma das vantagens do uso da $\mathrm{AF}$ é que não é necessário o conhecimento do número ou a composição das fontes de aerossóis. A variabilidade original dos dados é descrita em termos de um número menor de variáveis aleatórias, as quais são chamadas de fatores comuns ${ }^{17}$. A verificação da variabilidade dos dados, por sua vez, envolve a avaliação das variâncias, covariâncias e a correlação entre eles ${ }^{23}$.

Um dos critérios adotado para construir o modelo de AF é a escolha do método para estimar as matrizes relativas às variâncias das variáveis padronizadas e às variâncias dos erros aleatórios. Três métodos de estimação podem ser utilizados: análise de componentes principais, de fatores principais e da máxima verossimilhan$\mathrm{ça}^{24}$. Dentre estes o método das componentes principais foi o adotado devido ao fato de não exigir informações ou suposições sobre a distribuição de probabilidades das variáveis padronizadas ${ }^{25}$.

Para a realização da análise fatorial, foi utilizado o software estatístico SPSS ("Statistical Package for the Social Science"), versão 10.0. Os demais procedimentos de cálculos foram realizados com o suporte de planilhas eletrônicas geradas no programa Excel da Microsoft.

\section{RESULTADOS E DISCUSSÃO}

\section{Qualidade do ar e tamanho das partículas}

Na Tabela 1 são apresentados os resultados das concentrações médias de material particulado total em suspensão (PTS) e os respectivos índices de qualidade do ar. Pode-se notar que apenas $28 \%$ das observações das concentrações de PTS não ultrapassaram o padrão primário diário (concentração média de 24 h igual a $240 \mu \mathrm{g}$ $\mathrm{m}^{-3}$ ). No restante dos dias, o padrão primário diário foi ultrapassado, ou seja, durante o período de amostragem, o padrão primário diário foi ultrapassado 23 vezes (77\% dos dias).

A legislação ambiental estabelece que o padrão primário diário não pode ser excedido mais de uma vez ao ano ${ }^{1}$. Se for considerado como referência o padrão secundário diário $\left(150 \mu \mathrm{g} \mathrm{m}^{-3}\right)$ para partículas totais em suspensão (PTS), a situação é ainda mais crítica. Neste caso, o limite só não foi ultrapassado 2 vezes. A qualidade do ar apresentou-se na faixa Regular em $21 \%$ dos dias, em $38 \%$ dos dias na faixa Inadequada, em $38 \%$ na faixa de Má qualidade e em 3\% na faixa Péssima.

Na Tabela 2 são mostrados os resultados das concentrações médias diárias de partículas inaláveis $\left(\mathrm{PM}_{10}\right)$ relacionados com os respectivos índices de qualidade do ar. Os resultados não excederam o padrão primário diário de concentração média de 24 h, cujo valor é igual a $150 \mu \mathrm{g} \mathrm{m}^{-3}$, estabelecido pela legislação ambiental federal e adotado em Minas Gerais. O padrão secundário diário, que também é de $150 \mu \mathrm{g} \mathrm{m}^{-3}$, não foi excedido. Em $53 \%$ dos dias amostrados, a qualidade do ar apresentou-se na faixa Regular, ou seja, as concentrações médias de $\mathrm{PM}_{10}$ foram superiores a $50 \mu \mathrm{g} \mathrm{m} \mathrm{m}^{-3}$.

Durante todo o período de amostragem do material particulado presente no aerossol atmosférico de Sete Lagoas foram feitas medições de parâmetros meteorológicos na região de estudo, entre eles, a velocidade e a direção do vento no local de amostragem do material particulado. Para tanto, foi montada uma estação meteoro- 
Tabela 1. Resultados das concentrações médias das partículas totais em suspensão (PTS) com os respectivos índices de qualidade do ar

\begin{tabular}{|c|c|c|c|}
\hline $\begin{array}{l}\text { Identificação } \\
\text { das Amostras }\end{array}$ & $\begin{array}{c}\text { Data da } \\
\text { Amostragem }\end{array}$ & $\begin{array}{l}\text { Concentração } \\
\text { Média }\left(\mu \mathrm{g} \mathrm{m}^{-3}\right)\end{array}$ & $\begin{array}{c}\text { Índice de } \\
\text { Qualidade do Ar }\end{array}$ \\
\hline PTS1 & $11 / 01 / 2005$ & 246 & Inadequada \\
\hline PTS2 & $12 / 01 / 2005$ & 327 & Inadequada \\
\hline PTS3 & $13 / 01 / 2005$ & 432 & Má \\
\hline PTS4 & $14 / 01 / 2005$ & 406 & Má \\
\hline PTS5 & $15 / 01 / 2005$ & 393 & Má \\
\hline PTS6 & $16 / 01 / 2005$ & 215 & Regular \\
\hline PTS7 & $17 / 01 / 2005$ & 331 & Inadequada \\
\hline PTS8 & $18 / 01 / 2005$ & 463 & Má \\
\hline PTS9 & $19 / 01 / 2005$ & 647 & Péssima \\
\hline PTS10 & $25 / 01 / 2005$ & 478 & Má \\
\hline PTS11 & $26 / 01 / 2005$ & 322 & Inadequada \\
\hline PTS12 & $27 / 01 / 2005$ & 258 & Inadequada \\
\hline PTS13 & 28/01/2005 & 361 & Inadequada \\
\hline PTS14 & $29 / 01 / 2005$ & 371 & Inadequada \\
\hline PTS15 & $30 / 01 / 2005$ & 226 & Regular \\
\hline PTS16 & $31 / 01 / 2005$ & 378 & Má \\
\hline PTS17 & $01 / 02 / 2005$ & 149 & Regular \\
\hline PTS18 & $02 / 02 / 2005$ & 380 & Má \\
\hline PTS19 & 03/02/2005 & 525 & Má \\
\hline PTS20 & $04 / 02 / 2005$ & 503 & Má \\
\hline PTS21 & $05 / 02 / 2005$ & 334 & Inadequada \\
\hline PTS22 & $06 / 02 / 2005$ & 250 & Inadequada \\
\hline PTS23 & $07 / 02 / 2005$ & 143 & Regular \\
\hline PTS24 & 08/02/2005 & 423 & Má \\
\hline PTS25 & $09 / 02 / 2005$ & 370 & Inadequada \\
\hline PTS26 & $10 / 02 / 2005$ & 395 & Má \\
\hline PTS27 & $11 / 02 / 2005$ & 227 & Regular \\
\hline PTS28 & $12 / 02 / 2005$ & 200 & Regular \\
\hline PTS29 & $13 / 02 / 2005$ & 364 & Inadequada \\
\hline
\end{tabular}

lógica no mesmo local de coleta do material particulado. Os resultados mostraram que a maioria das fontes de emissão, tais como concreteiras, fabricação de produtos cerâmicos e produção de ferro-gusa a carvão vegetal, está localizada no setor leste da cidade de Sete Lagoas e, portanto, no setor dos ventos predominantes (leste para oeste), o que contribui ainda mais para a degradação da qualidade do ar na região.

A campanha de amostragem para determinação do tamanho das partículas ocorreu nos dias 3, 4 e 5/8/2005. Os resultados obtidos em cada uma delas estão apresentados na Figura 1, onde se tem a concentração de material particulado em função do tamanho das partículas do aerossol atmosférico. A determinação da distribuição do tamanho das partículas dos aerossóis atmosféricos sugeriu que aproximadamente $80 \%$ das partículas amostradas possuem diâmetro aerodinâmico menor que $2,5 \mu \mathrm{m}$.

\section{Análise da composição mineralógica}

Os resultados das análises de difração de raios-X para determinação da composição mineralógica do material particulado presente no aerossol atmosférico do município de Sete Lagoas, MG, são apresentados na Tabela 3. Conforme pode ser verificado, a calcita está presente, tanto no material particulado inalável e como no particulado total em suspensão, em uma freqüência maior que $30 \%$. O quartzo é predominante na categoria de 30 a $10 \%$. As variações de fases cristalinas para as duas frações de material particulado só foram observadas nas freqüências abaixo de $10 \%$.
Tabela 2. Resultados das concentrações médias de partículas inaláveis $\left(\mathrm{PM}_{10}\right)$ e dos respectivos índices de qualidade do ar

\begin{tabular}{|c|c|c|c|}
\hline $\begin{array}{l}\text { Identificação } \\
\text { das Amostras }\end{array}$ & $\begin{array}{c}\text { Data da } \\
\text { Amostragem }\end{array}$ & $\begin{array}{l}\text { Concentração } \\
\text { Média }\left(\mu \mathrm{g} \mathrm{m} \mathrm{m}^{-3}\right)\end{array}$ & $\begin{array}{c}\text { Índice de } \\
\text { Qualidade do Ar }\end{array}$ \\
\hline PI1 & $11 / 01 / 2005$ & 73 & Regular \\
\hline PI2 & $12 / 01 / 2005$ & 71 & Regular \\
\hline PI3 & $13 / 01 / 2005$ & 58 & Regular \\
\hline PI4 & $14 / 01 / 2005$ & 68 & Regular \\
\hline PI5 & $15 / 01 / 2005$ & 39 & Boa \\
\hline PI6 & $16 / 01 / 2005$ & 62 & Regular \\
\hline PI7 & $17 / 01 / 2005$ & 41 & Boa \\
\hline PI8 & $18 / 01 / 2005$ & 66 & Regular \\
\hline PI9 & $19 / 01 / 2005$ & 67 & Regular \\
\hline PI10 & $20 / 01 / 2005$ & 82 & Regular \\
\hline PI11 & $25 / 01 / 2005$ & 28 & Boa \\
\hline PI12 & $26 / 01 / 2005$ & 72 & Regular \\
\hline PI13 & $27 / 01 / 2005$ & 18 & Boa \\
\hline PI14 & $28 / 01 / 2005$ & 42 & Boa \\
\hline PI15 & $29 / 01 / 2005$ & 47 & Boa \\
\hline PI16 & $30 / 01 / 2005$ & 25 & Boa \\
\hline PI17 & $31 / 01 / 2005$ & 76 & Regular \\
\hline PI18 & $01 / 02 / 2005$ & 16 & Boa \\
\hline PI19 & $02 / 02 / 2005$ & 57 & Regular \\
\hline PI20 & $03 / 02 / 2005$ & 132 & Regular \\
\hline PI21 & $04 / 02 / 2005$ & 102 & Regular \\
\hline PI22 & $05 / 02 / 2005$ & 33 & Boa \\
\hline PI23 & $06 / 02 / 2005$ & 17 & Boa \\
\hline PI24 & $07 / 02 / 2005$ & 63 & Regular \\
\hline PI25 & $08 / 02 / 2005$ & 48 & Boa \\
\hline PI26 & $09 / 02 / 2005$ & 65 & Regular \\
\hline PI27 & $10 / 02 / 2005$ & 96 & Regular \\
\hline PI28 & $11 / 02 / 2005$ & 25 & Boa \\
\hline PI29 & $12 / 02 / 2005$ & 39 & Boa \\
\hline PI30 & $13 / 02 / 2005$ & 42 & Boa \\
\hline
\end{tabular}

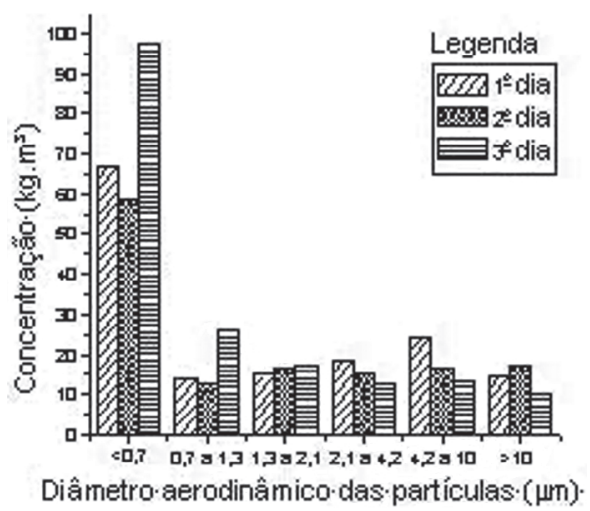

Figura 1. Concentração total de material particulado em função do diâmetro aerodinâmico das partículas

\section{Análise da composição elementar}

Na Figura 2 são apresentados os resultados das concentrações elementares dos elementos químicos mais significativos presentes no material particulado amostrado.

Como pode ser observado, $\mathrm{Al}$ e $\mathrm{Fe}$ são os elementos predominantes nas partículas totais em suspensão (PTS). A literatura ${ }^{24-26}$ relata que esses elementos são geralmente associados a traçadores do solo e da indústria siderúrgica. $\mathrm{Na}$ seqüência, têm-se $\mathrm{Cl}, \mathrm{Cu}, \mathrm{K}$, $\mathrm{Mg}$ e $\mathrm{Na}$, que são elementos que podem ser associados aos proces- 
Tabela 3. Resultados da análise por difração de raios- $X$ do material particulado presente no aerossol atmosférico

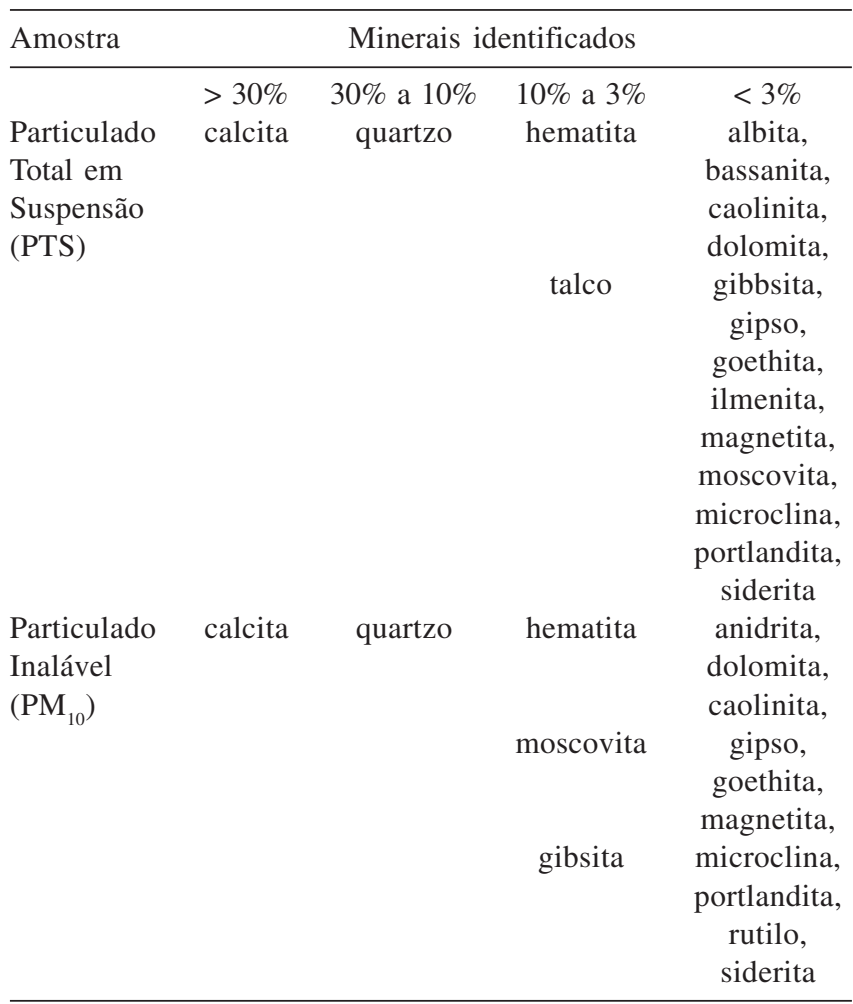

sos de queima de combustíveis fósseis e vegetais. Por último, destacam-se Ti, que é normalmente associado a elemento traçador do solo, e Zn, o qual pode ser associado à produção de ligas de latão, processos de transformação de cimento e queima de carvão.

$\mathrm{O}$ material particulado inalável $\left(\mathrm{PM}_{10}\right)$ também é constituído de grupos distintos: o primeiro grupo destaca-se pela elevada concentração de $\mathrm{Cu}$ e $\mathrm{Na}$, os quais podem ser associados a processos industriais com queima de combustível fóssil ${ }^{26,27}$. O Fe aparece destacado seguido do terceiro grupo onde estão presentes $\mathrm{Ba}, \mathrm{Cl}$, Eu e $\mathrm{Sm}$, os quais podem ser associados a processos industriais e à ressuspensão do solo.

Alguns elementos aparecem no material particulado total em suspensão e outros no particulado inalável. Isto pode ser explicado pelo fato do processo de formação do material particulado presente no aerossol atmosférico ser distinto. Como mencionado anteriormente, as partículas com diâmetro maior são formadas a partir de processos mecânicos, como exemplo, a ressuspensão de poeira de solo por ventos. As partículas inaláveis, ou seja, aquelas com diâmetro aerodinâmico $<10 \mu \mathrm{m}$, são geradas, principalmente, por processos de combustão de fontes industriais e, portanto, é de se esperar que a sua composição química seja diferente daquelas com diâmetro maior.

\section{Análise estatística dos dados}

No presente estudo, em função do número de variáveis (elementos químicos) ser muito maior que o número de observações (amostras), a análise exploratória foi reduzida devido ao elevado número de parâmetros a serem estimados. Quanto maior o número de parâmetros a serem estimados, menor o número de graus de liberdade e, conseqüentemente, a precisão da análise será menor ${ }^{24,25}$. Essas condições iniciais se fazem presentes ao longo da análise estatística para os dados referentes ao material particulado total em suspensão e ao particulado inalável.
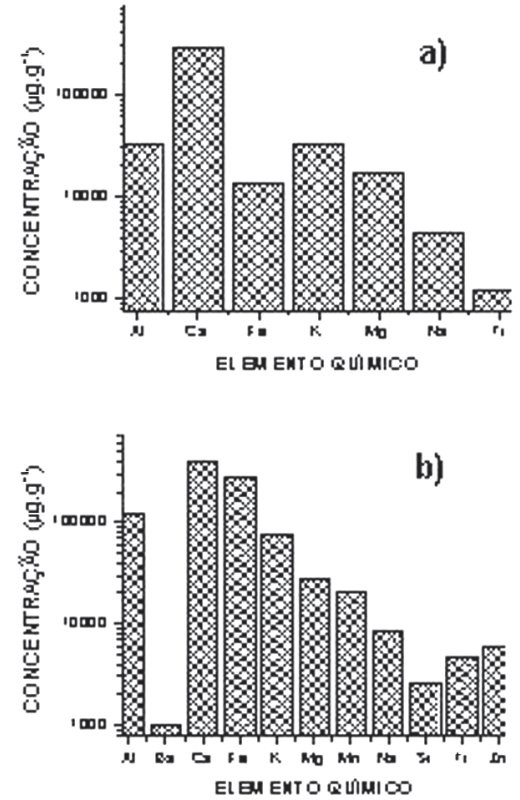

Figura. 2. Concentrações elementares dos principais elementos químicos presentes no material particulado; a) partículas totais em suspensão (PTS) $e$ b) partículas inaláveis $\left(P M_{10}\right)$

A análise de componentes principais para o material particulado total em suspensão (PTS) foi realizada utilizando 12 variáveis (concentrações de $\mathrm{Al}, \mathrm{As}, \mathrm{Cl}, \mathrm{Cu}, \mathrm{Fe}, \mathrm{K}, \mathrm{Mg}, \mathrm{Mn}, \mathrm{Na}, \mathrm{Sm}, \mathrm{Ti}, \mathrm{V}$ ) com 29 observações. A escolha do número de fatores retidos foi feita com base na fração de explicação da variância total, na variabilidade das variáveis individuais e nos autovalores maiores que 1 . O modelo ajustado apresentou 3 fatores, os quais explicam 79,3\% da variabilidade dos dados. O fator 1 explicou $46 \%$ da variância total, o fator 2 explicou $24 \%$ e o fator 3 representou aproximadamente $9 \%$ da variância.

Além dos valores de variabilidade total atribuída aos fatores retidos foram avaliadas as variabilidades individuais explicadas pelo modelo proposto. Como pode ser observado na Tabela 5 as comunalidades $\left(\mathrm{h}^{2}\right)$ relativas a cada variável considerada no modelo mostraram-se significativas, apresentando valores superiores a 0,78 . Para as variáveis $\mathrm{Cu}, \mathrm{Mn}$ e $\mathrm{Sm}$, o modelo explica mais de $90 \%$. O modelo explica também mais de $80 \%$ da variabilidade do As, Fe, K e V.

Os resultados expressos na Tabela 4 foram obtidos após rotação Varimax das componentes principais. A rotação foi realizada para proporcionar uma melhor clareza nas cargas fatoriais, possibilitando a identificação do fator com uma fonte poluidora conhe$\operatorname{cida}^{27}$. Conforme pode ser verificado, o fator 1 possui altos pesos para $\mathrm{Sm}, \mathrm{Cu}, \mathrm{As}$ e $\mathrm{Na}$. Estes elementos podem ser associados à extração e/ou beneficiamento de calcário, fabricação de concreto e produtos cerâmicos, bem como a outros tipos de processos industriais. $\mathrm{O}$ fator 2 tem os elementos $\mathrm{Mn}$ e Fe como maiores participantes, os quais sugerem a associação à fonte solo e à produção de ferro-gusa a carvão vegetal. O fator 3 tem altos pesos para $\mathrm{V}, \mathrm{Al}, \mathrm{K}$, apresentando também uma boa contribuição do Ti. Estes elementos estão associados, principalmente, à fonte solo e à queima de óleo combustível usado em caldeiras ${ }^{3,26}$.

Para as concentrações elementares do material particulado inalável $\left(\mathrm{PM}_{10}\right)$ foi realizada análise de componentes principais com 10 variáveis (concentrações de Al, Ba, Cr, Fe, Dy, Mg, Mn, Na, V, Zn) e com 30 observações. Foram consideradas as variáveis completas, sendo que apenas uma apresentou casos faltantes da ordem de $10 \%$. 
Tabela 4. Pesos e comunalidades obtidas na análise de componentes principais para particulados totais em suspensão

\begin{tabular}{lcccc}
\hline $\begin{array}{l}\text { Elemento } \\
\text { Químico }\end{array}$ & 1 & $\begin{array}{c}\text { Fatores } \\
2\end{array}$ & 3 & $\begin{array}{c}\text { Comunalidade } \\
\mathrm{h}^{2}\end{array}$ \\
\hline Al & 0,126 & 0,289 & $\mathbf{0 , 8 6 9}$ & 0,885 \\
As & $\mathbf{0 , 8 8 4}$ & 0,250 & 0,127 & 0,866 \\
$\mathbf{C l}$ & 0,298 & 0,311 & 0,155 & 0,825 \\
$\mathbf{C u}$ & $\mathbf{0 , 9 1 7}$ & 0,184 & 0,058 & 0,878 \\
Fe & 0,200 & $\mathbf{0 , 8 9 6}$ & 0,261 & 0,911 \\
$\mathbf{K}$ & 0,065 & 0,189 & $\mathbf{0 , 7 5 9}$ & 0,789 \\
$\mathbf{M g}$ & 0,177 & 0,696 & 0,393 & 0,813 \\
$\mathbf{M n}$ & 0,008 & $\mathbf{0 , 9 3 3}$ & 0,184 & 0,936 \\
$\mathbf{N a}$ & $\mathbf{0 , 8 8 0}$ & $-0,024$ & 0,209 & 0,938 \\
$\mathbf{S m}$ & $\mathbf{0 , 9 4 1}$ & 0,006 & $-0,135$ & 0,906 \\
Ti & $-0,001$ & 0,604 & 0,632 & 0,779 \\
$\mathbf{V}$ & 0,001 & 0,220 & $\mathbf{0 , 8 3 3}$ & 0,877 \\
\hline
\end{tabular}

O modelo adotado foi aquele com 4 fatores retidos e que apresentaram autovalores maiores que 1 . A variância total explicou $77,5 \%$ da variabilidade dos dados. O fator 1 explicou $31,5 \%$ da variância total, o fator 2 explicou $20,1 \%$ e os fatores 3 e 4 explicaram, respectivamente, 13,9 e 11,9 da variância total do modelo.

Da mesma forma procedida na análise do PTS, os dados apresentados na Tabela 5 são resultados da aplicação da análise de componentes principais após rotação Varimax. Os resultados indicam que o modelo de 4 fatores representa satisfatoriamente as variáveis originais.

O peso associado a cada variável componente de um fator está associado à correlação entre o elemento e o fator retido. $\mathrm{O}$ fator 1 tem maiores valores atribuídos para $\mathrm{Ba}, \mathrm{Fe}$ e $\mathrm{Cr}$, os quais são elementos associados à indústria siderúrgica. $\mathrm{O}$ fator 2 tem altos pesos para Mn e Dy, os quais estão associados à fonte solo. $\mathrm{O}$ fator 3 possui maiores valores para $\mathrm{Al}$ e $\mathrm{V}$, os quais provavelmente estão associados à queima de combustíveis e à fonte solo. $\mathrm{O}$ fator 4 é mais bem explicado pelo $\mathrm{Na}$ e $\mathrm{Zn}$, que estão associados à fabricação de concreto e de produtos cerâmicos.

Como no modelo para PTS, os valores negativos não são representativos nesta análise, pois seus valores absolutos não são aproximados de 1 .

Tabela 5. Pesos e comunalidades obtidas na análise de componentes principais para partículas inaláveis

\begin{tabular}{lccccc}
\hline $\begin{array}{l}\text { Elemento } \\
\text { Químico }\end{array}$ & 1 & 2 & 3 & 4 & $\begin{array}{c}\text { Comunalidade } \\
\mathrm{h}^{2}\end{array}$ \\
\hline $\mathrm{Al}$ & $-0,030$ & 0,115 & $\mathbf{0 , 8 8 5}$ & $-0,058$ & 0,818 \\
$\mathrm{Ba}$ & $\mathbf{0 , 9 4 8}$ & $-0,085$ & $-0,058$ & 0,002 & 0,914 \\
$\mathrm{Cr}$ & $\mathbf{0 , 9 4 1}$ & $-0,193$ & $-0,041$ & $-0,010$ & 0,926 \\
$\mathrm{Dy}$ & $-0,284$ & $\mathbf{0 , 8 7 0}$ & $-0,072$ & $-0,017$ & 0,854 \\
$\mathrm{Fe}$ & $\mathbf{0 , 7 7 4}$ & $-0,054$ & $-0,102$ & 0,391 & 0,780 \\
$\mathrm{Mg}$ & $-0,016$ & 0,040 & 0,005 & 0,051 & 0,971 \\
$\mathrm{Mn}$ & $-0,015$ & $\mathbf{0 , 8 9 0}$ & 0,192 & 0,099 & 0,842 \\
$\mathrm{Na}$ & $-0,055$ & 0,309 & 0,205 & $\mathbf{0 , 8 4 7}$ & 0,870 \\
$\mathrm{~V}$ & $-0,116$ & 0,004 & $\mathbf{0 , 8 8 6}$ & 0,190 & 0,856 \\
$\mathrm{Zn}$ & 0,357 & $-0,219$ & $-0,059$ & $\mathbf{0 , 7 4 8}$ & 0,796 \\
\hline
\end{tabular}

\section{CONCLUSÕES}

O material particulado presente nos aerossóis atmosféricos da cidade de Sete Lagoas apresentou condição inadequada da qualidade do ar na região. No caso do material particulado total em suspensão (PTS), foi verificado que 76\% dos dias correspondentes ao período de amostragem apresentaram qualidade do ar considerada Inadequada ou Má. Por outro lado, em 53\% desses dias, a qualidade do ar para as partículas inaláveis $\left(\mathrm{PM}_{10}\right)$ foi considerada como Regular.

A distribuição do tamanho das partículas delineou um cenário preocupante, uma vez que $80 \%$ das partículas presentes no aerossol atmosférico referem-se às frações de partículas com diâmetro aerodinâmico menor que $2,5 \mu \mathrm{m}$ correspondendo, portanto, em sua maioria, àquela fração que pode atingir as vias respiratórias inferiores (nível alveolar) e provocar sérios danos à saúde humana.

Os processos de amostragem e analítico utilizados mostraram que é possível identificar quantitativamente as principais fontes de material particulado presente no aerossol de um centro urbano de médio porte como Sete Lagoas, MG.

A técnica de análise por ativação neutrônica mostrou-se eficiente para as análises das amostras de material particulado depositado sobre os filtros de celulose e microssílica utilizados para a coleta de PTS e $\mathrm{PM}_{10}$, respectivamente. Com essa metodologia não há necessidade de preparação das amostras e as análises são multielementares, simultâneas e não destrutivas, o que permitiu a determinação de vários elementos no material particulado com número atômico compreendido entre 13 (Al) e 238 (U). Entretanto, ela deve ser complementada por outra técnica analítica para que elementos químicos importantes do ponto de vista ambiental, como $\mathrm{Si}, \mathrm{Cd}, \mathrm{Ca}, \mathrm{Pb}$, também possam ser determinados. De maneira geral, os elementos químicos predominantes no material particulado presente nos aerossóis foram $\mathrm{Al}, \mathrm{Ca}, \mathrm{Fe}, \mathrm{K}, \mathrm{Mg}$ e $\mathrm{Na}$.

A análise da composição mineralógica pelo método de difração de raios-X indicou que os minerais presentes em maior abundância, tanto no PTS como no $\mathrm{PM}_{10}$ são a calcita (>30\%) e quartzo (de 10 a $30 \%$ ), os quais estão associados, principalmente, aos processos de mineração do calcário e fabricação de produtos cerâmicos ${ }^{17}$. Os óxidos de ferro estão presentes nas frações menores que $10 \%$. Suas formas são variadas. Podendo-se destacar a hematita, magnetita e goethita.

Todos os resultados da análise por ativação neutrônica do material particulado foram submetidos a uma análise estatística multivariada. A aplicação de um modelo receptor utilizando a análise fatorial por meio do método de componentes principais permitiu a identificação e associação das fontes emissoras com a composição elementar das partículas totais em suspensão e das partículas inaláveis.

Para o particulado total em suspensão foram identificados 3 fatores. As fontes correspondentes à extração e beneficiamento de calcário, fabricação de concreto e produtos cerâmicos, bem como de outros processos industriais não identificados por meio da análise da composição elementar dos resíduos sólidos gerados, explicaram $46 \%$ da variabilidade do PTS. Os marcadores Mn e Fe identificaram as fontes solo e produção de ferro-gusa, representando $24 \%$ da variabilidade. A fonte queima de combustível e fonte solo explicaram $19 \%$ do modelo proposto.

$\mathrm{Na}$ análise estatística do particulado inalável $\left(\mathrm{PM}_{10}\right)$ foram identificados quatro fatores. $\mathrm{O}$ fator predominante, com explicação de $31 \%$ da variabilidade, foi aquele associado à indústria siderúrgica, ou seja, a produção de ferro-gusa a carvão vegetal. A fonte solo representou $20 \%$ da modelagem proposta. As associações às fontes queima de combustível e ao solo ficaram por conta dos $14 \%$, atribuídos às contribuições dos marcadores Mn e V. A fonte correspondente à fabricação de concreto e produtos cerâmicos representou $12 \%$ da contribuição ao modelo. O restante da variabilidade está provavelmente associado a outras fontes industriais menos expressivas e, portanto, não consideradas neste trabalho. 
A combinação de todas essas informações, juntamente com os dados meteorológicos (em especial, a direção predominante dos ventos) e os de posicionamento geográfico das fontes, sugerem que a poeira do solo e as fontes industriais, tais como aquelas relacionadas à produção de ferro-gusa a carvão vegetal e à fabricação de concreto e produtos cerâmicos, constituem-se nos maiores contribuintes de emissão do material particulado presente nos aerossóis atmosférico do local em estudo.

Um ponto importante a ser mencionado é o fato de que as matérias-primas utilizadas nas diferentes tipologias industriais consideradas no presente trabalho serem basicamente as mesmas. Portanto, é de se esperar que a composição elementar das diferentes fontes de emissão seja semelhante, o que dificulta o processo de identificação por meio do uso de modelos receptores. A obtenção de dados mais conclusivos, bem como a redução das incertezas associadas aos resultados finais envolve não apenas um tempo de amostragem maior, mas também de um maior número de pontos representativos da região em estudo.

\section{AGRADECIMENTOS}

À Secretaria Municipal de Meio Ambiente de Sete Lagoas pelo apoio dado na coleta das amostras. Ao Dr. A. A. Barreto pela ajuda na montagem dos experimentos e ao geólogo W. de Brito pela realização das análises de composição mineralógica pela técnica de difração de raios-X.

\section{REFERÊNCIAS}

1. Conselho Nacional do Meio Ambiente (CONAMA); Resolução CONAMA № 003/90, 1990.

2. Alves, C.; Quim Nova 2005, 28, 859 .

3. Andrade, M. F.; Tese de Doutorado, Universidade de São Paulo, Brasil, 1993

4. Pandis, S. N.; Harley, R. A.; Cass, G. R.; Seinfeld, J. H.; Atmos. Environ. 1992, 26A, 2269.

5. Turpin, B.; Environ. Sci. Technol. 1999, 1, 76.

6. Seinfeld, J. H.; Atmospheric Chemistry and Physics from Air Pollution to Climate Change, Wiley: New York, 1986.

7. http://www.epa.gov/ttn/amtic/files/ambient/pm25/spec/drispec.pdf, acessada em Junho 2004.
8. Murray, F.; Impactos em La Salud, Estocolmo: SEI - Stochholm Environment Institute, 1998, Sección 2.1.

9. Lin, C. A.; Tese de Doutorado, Universidade de São Paulo, Brasil, 1997.

10. Fundação Estadual do Meio Ambiente (FEAM); Licenciamento Ambiental: Coletânea de Legislação, $2^{\mathrm{a}}$ ed., Projeto Minas Ambiente: Belo Horizonte, 2000.

11. Krull, I. S.; Trace Metal Analysis and Speciation, Elsevier: Amsterdam, 1991.

12. Lobinski, R.; Marczenko, Z.; Spectrochemical Trace Analysis for Metals and Metalloids, Elsevier: Amsterdam, 1996.

13. Artaxo, P.; Castanho, A. P.; Yamasoe, M. A.; Martins, J. V.; Longo, K. M.; Nucl. Instrum. Methods Phys. Res., Sect. B 1999, 150, 312.

14. Gose, M. H.; Paul, R.; Bernejee, R. K.; Environ. Monit. Assess. 2005, 108, 151.

15. Landsberger, S.; Creatchman, M.; Elemental Analysis of Airborne Particles, Gordon and Breach Science Publishers: Amsterdam, 1999.

16. Projeto Minas Ambiente; Ensino e Desenvolvimento Tecnológico para Controle Ambiental na Indústria. Subprojeto Ferro-Gusa. Monitoramento da Qualidade do Ar em Divinópolis e Sete Lagoas, Relatório de Avaliação dos Resultados - Período: Março/1999 a Fevereiro/2000, Belo Horizonte, 2000.

17. Queiroz, P. G. M.; Dissertação de Mestrado, Centro de Desenvolvimento da Tecnologia Nuclear, Brasil, 2006.

18. www.energetica.com.ar, acessada em Fevereiro 2006

19. Associação Brasileira de Normas Técnicas; NBR 9547-86 Material Particulado em Suspensão no Ar Ambiente - Determinação da concentração total pelo método do amostrador de grande volume - método de ensaio, São Paulo, 1986.

20. Associação Brasileira de Normas Técnicas; NBR 13412-95 Material Particulado em Suspensão na Atmosfera - Determinação da concentração de partículas inaláveis pelo método do amostrador de grande volume acoplado a um separador inercial de partículas - método de ensaio, São Paulo, 1995.

21. Menezes, M. Â. B. C.; Sabino, C. V. S.; Franco, M. B.; Kastner, G. F.; Rossi, E. H; J. Radioanal. Nucl. Chem. 2003, 257, 627.

22. Nation Institute of Standards and Technology (NIST); Particle Size characterization. Special Publication 960-I, Material Science Engineering Laborator, Washington, 2001.

23. Johnson, R. A.; Wichern, D. W.; Applied Multivariate Statistical Analysis, Prentice- Hall, Inc.: New Jersey, 1999.

24. Mingoti, S. A; Análise de dados através de métodos de estatística multivariada: Uma abordagem aplicada, Ed. UFMG: Belo Horizonte, 2005.

25. Sena, M. M.; Poppi, R. J.; Frighetto, R. T. S.; Valarini, P. J.; Quim. Nova 2000, 23, 547 .

26. Artaxo, P.; Tese de Doutorado, Universidade de São Paulo, Brasil, 1985.

27. Castanho, A. D. A.; Dissertação de Mestrado, Universidade de São Paulo, Brasil, 1999. 